\title{
Changes of ghrelin and leptin levels in plasma by cigarette smoke in rats
}

\author{
Koichi Tomoda', Kaoru Kubo², Yasue Nishii ${ }^{3}$, Yoshifumi Yamamoto', \\ Masanori Yoshikawa ${ }^{1}$ and Hiroshi Kimura ${ }^{1}$ \\ ${ }^{1}$ Second Department of Internal Medicine, '2aboratory Animal Research Center, Nara Medical University, \\ 840 Shijocho, Kashihara City, Nara 634-8522, Japan \\ ${ }^{3}$ Faculity of Health Science, Kio University, 4-22 Umami-naka, Korhyocho, Kitakatsuragigun, Nara 635-0832, Japan
}

(Received September 23, 2011; Accepted November 14, 2011)

\begin{abstract}
Cigarettes smoke (CS) limits food intake and body weight increase. Ghrelin and leptin are hormones regulating appetite and energy balance. While ghrelin increases food intake and causes a positive energy balance, leptin decreases food intake and enhances a negative energy balance. To investigate the possible role of ghrelin and leptin regarding the negative energy balance caused by CS, 10-week old male Wistar rats $(n=10)$ were exposed to CS from 30 cigarettes twice a day for 5 days a week for four weeks. In the smoking group, food intake and body weight gain were less than those in the nonsmoking group $(\mathrm{n}=10)$ during the entire CS exposure. In the smoking group, the plasma levels of acyl ghrelin were significantly higher $(75.9 \pm 5.1 \mathrm{fmol} / \mathrm{ml}$ versus $46.5 \pm 3.3 \mathrm{fmol} / \mathrm{ml}, \mathrm{p}<0.01)$, while those of leptin were significantly lower than those in the non-smoking group $(434.9 \pm 41.1 \mathrm{ng} / \mathrm{ml}$ versus $744.0 \pm$ $45.4 \mathrm{ng} / \mathrm{ml}, \mathrm{p}<0.01)$ after the final CS exposure. However, the plasma des-acyl ghrelin levels were not affected by CS exposure. These results suggested that acyl ghrelin and leptin levels in plasma may change to compensate for the negative energy balance by CS.
\end{abstract}

Key words: Cigarette smoke, Energy balance, Food intake, Ghrelin, Leptin

\section{INTRODUCTION}

Epidemiologic studies have demonstrated that cigarette smokers weighted less than nonsmokers of same age and gender, and also that anorexia is commonly observed among smokers (Albanes et al., 1987; Klesges et al., 1989). Both a decrease in food intake (Fulkerson and French, 2003) and an increase of energy expenditure (Chen et al., 2007) are thought to contribute to the negative energy balance caused by cigarette smoke. However how cigarette smoke causes negative energy balance has not been fully elucidated.

Energy homeostasis is closely regulated by a complex network of peripheral mediators, such as hormones, neuropeptides and cytokines. Ghrelin and leptin are hormones linked to these mediators. Ghrelin has been shown to elicit the potency, namely, the long-lasting stimulation of food intake through the activation of neuropeptides $Y$ (NPY) neurons in the hypothalamic arcuate nucleus in rats and mice (Shintani et al., 2001; Tschop et al., 2000;
Wren et al., 2000). Leptin, is one of the peptides derived from the adipocytes. It is produced in differentiated adipocytes and causes the inhibition of both NPY and agouti-related peptide (AgRP) neurons followed by a suppression of appetite (Halaas et al., 1995) and an enhancement of energy expenditure (Collins et al., 1996).

In underweight patients with chronic obstructive pulmonary disease (COPD), anorexia nervosa, and cancer cachexia, plasma ghrelin levels increased (Itoh et al., 2004; Otto et al., 2001; Shimizu et al., 2003), while plasma leptin levels decreased (Takabatake et al., 1999; Schols et al., 1999; Grinspoon et al., 1996; Simons et al., 1997). COPD is mainly caused by cigarette smoke and has been recognized as a systemic disease. Malnutrition is one of the systemic effects in COPD (Takabatake et al., 1999; Schols et al., 1999). However it has not been fully elucidated how the malnutrition in COPD develops. Cigarette smoke contributes to the systemic effects in COPD (Fabbri et al., 2007). Negative energy balance caused by cigarette smoke may contribute to malnutrition in COPD but the

Correspondence: Koichi Tomoda (E-mail: ktomoda@naramed-u.ac.jp) 
relationship is unclear.

In the present study, in order to investigate the role of ghrelin and leptin regarding the negative energy balance induced by cigarette smoke we measured plasma levels of ghrelin and leptin in rats after four weeks exposure to cigarette smoke.

\section{MATERIALS AND METHODS}

All procedures performed during these animal experiments were approved by our Instititional Ethics Committee in accordance with The Guidelines for Animal Experiments in Nara Medical University and the Guiding Principles for the Care and Use of Laboratory Animals approved by The Japanese Pharmacological Society.

\section{Experimental animals and cigarette smoke exposure}

Ten-week-old, male Wistar Kyoto (WKY/Izm) rats were purchased from Japan SLC, Inc. (Shizuoka, Japan), and fed with commercial solid diet (CE-2; CLEA Japan, Inc., Tokyo, Japan) and water ad libitum throughout the preconditioning and experimental periods in the laboratory animal research center at Nara Medical University. Animals were kept in a limited-access barrier housing maintained at a room temperature of $22 \pm 1{ }^{\circ} \mathrm{C}$, within humidity level of $55 \pm 10 \%$, and a $12 \mathrm{hr}$ light/dark cycle, with illumination from 08:00 to 20:00.

Animals were compulsively exposed to cigarette smoke using a Hamburg II smoking apparatus (Borgwaldt, Germany) according to the method the present authors have reported (Tomoda et al., 2011). All smoke exposure experiments were carried out using Hi-lite ${ }^{\circledR}$ filter cigarettes (Japan Tobacco Industry Co., Ltd., Tokyo, Japan), which have nicotine and tar contents $1.4 \mathrm{mg}$ and $17 \mathrm{mg}$ per cigarette, respectively. The cigarette was smoked at a rate of 15 puffs per minute with an inhalation of 2 sec of smoke, mixed with 7 volumes of air, followed by $2 \mathrm{sec}$ of air in the chamber. The mixture of air and smoke was moved to the 10 holders each containing one animal connected through the chamber. Preliminari- ly, the percent carboxyhemoglobin $(\mathrm{CO}-\mathrm{Hb})$ was determined spectrophotometrically with CO-Oxymeter (GEM Premier 4000, Nihon Medi. Science Co., Ltd., Gunma Pref., Japan) on fresh heparin-anticoagulated blood aliquots (100 UI heparin $/ \mathrm{ml}$ blood) taken before and at defined intervals after cigarette smoke exposure from the middle caudal artery in animals under anesthesia with pentobarbital sodium (Nembutal ${ }^{\circledR}, 50 \mathrm{mg} / \mathrm{kg}$ i.p.; Abbott Laboratories, Abbott Park, IL, USA). Seven animals were used for the determination of the $\% \mathrm{CO}-\mathrm{Hb}$ at each time point (Table 1).

Animals were randomly divided into two groups (10 animals per group) and 10 animals in the smoking group were exposed to smoke from 30 cigarettes twice a day for 5 days a week, (Monday to Friday) for four weeks. Ten animals in the non-smoking group were also kept in the Hamburg II apparatus holders but without exposure to cigarette smoke. Body weight was measured every Saturday. The food intake was calculated from the feeding volume beginning on Monday and subtracting the residual volume on Saturday for each individual animal.

\section{Anti-oxidant/oxidant balance in plasma}

At $12 \mathrm{hr}$ after the final cigarette-smoke exposure, whole blood was collected from the abdominal artery of each animal in each group, under anesthesia with pentobarbital sodium ( $50 \mathrm{mg} / \mathrm{kg}$ i.p.). The plasma was separated by centrifugation and stored at $-80^{\circ} \mathrm{C}$ until determination of anti-oxidant/oxidant balance in plasma by evaluation total anti-oxidant capacity and hydroperoxides levels in plasma (OXY-adsorbent and Diacron-Reactive Oxygen Metabolites [d-ROMs] tests, Diacron, Grosseto, Italy).

Total anti-oxidant capacity was measured by a spectrophotometric assay, OXY-adsorbent Test (OXY) of a plasma sample (Vassalle et al., 2008). This test is based on the capacity of hypochlorous acid $(\mathrm{HClO})$ to oxidize physiological antioxidants. Total antioxidant capacity can be obtained by evaluating the capacity to inactivate the oxidant solution $(\mathrm{HClO})$ added in excess to the sample. As $\mathrm{HClO}$ reacts with a chromogenic substrate $(\mathrm{N}, \mathrm{N}-$ diethyl-paraophenylendiamine), a colored complex devel-

Table 1. Influences of cigarette smoke exposure on carboxyhemoglobin levels in arterial blood

\begin{tabular}{|c|c|c|c|}
\hline Time (min) after exposure & Before exposure & $20 \mathrm{~min}$ & $40 \mathrm{~min}$ \\
\hline CO-hemoglobin (\%) & $1.0 \pm 0.2$ & $18.6 \pm 3.4^{* *}$ & $14.0 \pm 2.9^{* *}$ \\
\hline
\end{tabular}


Cigarette smoke changes ghrelin and leptin levels

ops that can be measured photometrically. The spectrophotometric measurement was determined within 1 min of incubation at room temperature, at a wavelength of $540 \mathrm{~nm}$. The concentration of the colored complex is directly proportional to the concentration of $\mathrm{HClO}$ and indirectly proportional to the anti-oxidant capacity. The results were expressed as $\mu \mathrm{mol}$ of $\mathrm{HClO}$ consumed by $1 \mathrm{ml}$ of the sample ( $\mu \mathrm{mol} \mathrm{HClO} / \mathrm{ml})$.

The oxidative status in plasma was evaluated as hydroperoxide levels measured by the [d-ROMs] test (Cesarone et al., 1999; Alberti et al., 2000). The hydroperoxides are the products of dehydrogenation and peroxidation of several cellular components including proteins, peptides, amino acids, lipids and fatty acids. When samples are dissolved in an acidic buffer, the hydroperoxides react with the transitional metal iron ions liberated from the proteins in the acidic medium and are converted to alkoxy and peroxy radicals. They can oxidize an additive ( $\mathrm{N}, \mathrm{N}$-diethyl-paraophenylendiamine) to the corresponding radical cation. The concentrations can be easily determined through spectrophotometric procedures (absorption at $505 \mathrm{~nm}$ ).

\section{Estimation of ghrelin levels and leptin levels in plasma}

At $12 \mathrm{hr}$ after the final cigarette-smoke exposure, whole blood was collected from the abdominal aorta of each animal in each group, under anesthesia with pentobarbital sodium $\left(\mathrm{Nembutal}^{\circledR}, 50 \mathrm{mg} / \mathrm{kg}\right.$ i.p.). Until the blood collection all animals were fed ad libitum. Whole blood samples were immediately transferred to chilled polypropylene tubes containing EDTA-2Na $(1 \mathrm{mg} / \mathrm{ml})$ and aprotinin (1000 kallikrein inactivator units per milliliter) and were immediately separated to plasma samples by centrifugation at $4^{\circ} \mathrm{C}$. Hydrogen chloride was immediately added to plasma samples, which were adjusted to a final concentration of $0.1 \mathrm{~N}$. These procedures were needed to avoid any fragmentation or inactivation of ghrelin because ghrelin is very unstable. These plasma samples were stored at $-80^{\circ} \mathrm{C}$ for subsequent determination of ghrelin levels. Acyl ghrelin and des-acyl ghrelin levels in plasma were measured by enzyme-linked immunosorbent assay (ELISA) kits (SCETI, Tokyo, Japan). The detection limits of the kit for acyl ghrelon and desacyl ghrelin were $2.5 \mathrm{fmol} / \mathrm{ml}$ and $12.5 \mathrm{fmol} / \mathrm{ml} \mathrm{respec-}$ tively.

Leptin levels in plasma were measured by ELISA (Yanaihara Institute, Shizuoka, Japan, Ohtsuka Institute, Tokyo, Japan respectively). The detection limit of the kit was $312.5 \mathrm{pg} / \mathrm{ml}$.

\section{Statistics}

Data were expressed as the means \pm S.D.. Comparisons of values between the two groups were analyzed by the Mann-Whitney U test. Comparison of \% $\mathrm{CO}-\mathrm{Hb}$ level before and $20 \mathrm{~min}$ or $40 \mathrm{~min}$ after exposure to cigarette smoke was performed by one-way analysis of variance, while comparison of body weight and food intake between the smoking and non-smoking groups were performed with two-way analysis of variance. A p-value of less than 0.05 was considered to indicate a statistically significant difference.

\section{RESULTS}

\section{Effect of cigarette smoke exposure on \% CO-Hb}

Table 1 shows that the \% CO-Hb level in plasma $20 \mathrm{~min}$ after cigarette smoke exposure was significantly higher than the levels before exposure and remained higher the entire $40 \mathrm{~min}$ follow-up period, and then returned to the baseline $12 \mathrm{hr}$ later (unpublished data). The recorded data correspond to measurements in human subjects, where plasma $\mathrm{CO}-\mathrm{Hb}$ levels of $18 \%$ are common in heavier smokers and 20\% in pipe smokers (Cole, 1981) (Table 1). In this study the peak \% CO-Hb level was $18.6 \%$ on average, which may be equivalent to those of heavier smokers.

Based on these results, we measured ghrelin and leptin levels as well as anti-oxidant/oxidant balance in plasma $12 \mathrm{hr}$ after the last exposure to cigarette smoke when there were only minimal direct effects by cigarette smoke.

\section{Effect of cigarette smoke exposure on food intake and body weight gain}

Figure 1 shows food intake at every week in the smoking and non-smoking groups. The food intake was measured as the amount of chow eaten by each animal twice a day for 5 days, from Monday to Friday. Food intake in the smoking group was significantly lower than that in the non-smoking group from the first week to the final week of the cigarette smoke exposure period $(\mathrm{p}<0.0001)$.

Figure 2 shows body weight at every week in the smoking and non-smoking groups. The body weight gain in the smoking group was significantly lower than that in the non-smoking group from the first week to the fourth week of cigarette smoke exposure $(p<0.0001)$.

\section{Anti-oxidant/oxidant balance in plasma}

In the smoking group, at $12 \mathrm{hr}$ after final smoke exposure d-ROM levels were lower and OXY levels were higher than those in the non-smoking group but without statistically significant differences. However the ratio of 


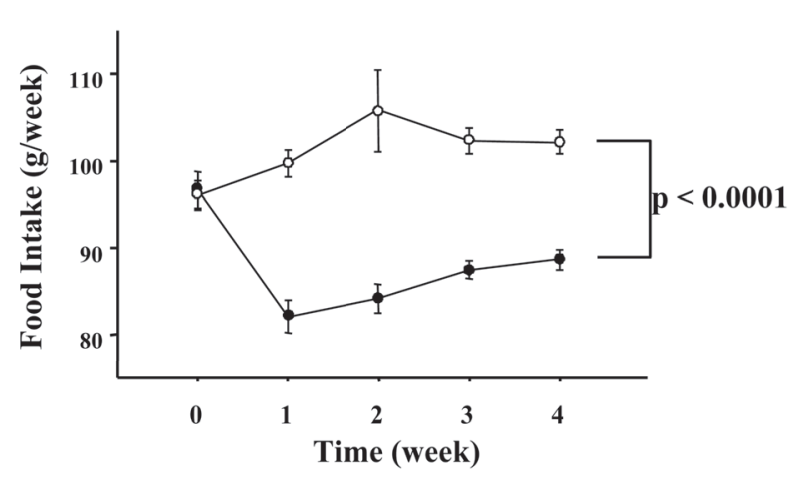

Fig. 1. Effects of cigarette smoke exposure on food intake in WKY rats. Circles show the mean values of the group not exposed to cigarette smoke, while solid dots are those of the smoke-exposed group. Each point indicates the mean \pm S.D. of 10 animals. Data were analyzed by two-way analysis of variance (ANOVA). The cigarette smoke-exposed group significantly differed from the cigarette smoke-unexposed group $(\mathrm{p}<0.0001)$.

OXY levels with regard to d-ROM levels in the smoking group was significantly higher than that in the non-smoking group $(\mathrm{p}=0.028)$ (Table 2$)$.

These findings suggest that anti-oxidant/oxidant balance in plasma is changed at $12 \mathrm{hr}$ after final cigarette smoke exposure.

\section{Effect of cigarette smoke exposure on plasma levels of ghrelin and leptin}

The plasma concentrations of acyl ghrelin, des-acyl ghrelin and leptin were evaluated $12 \mathrm{hr}$ after the final cigarette-smoke exposure. Plasma acyl ghrelin levels in the smoking group were significantly higher than those in the non-smoking group $(75.9 \pm 5.1 \mathrm{fmol} / \mathrm{ml}$ versus $46.5 \pm 3.3$ $\mathrm{fmol} / \mathrm{ml}, \mathrm{p}=0.0046)$. However there was no significant difference in des-acyl ghrelin levels between the smoking group and the non-smoking group $(433.7 \pm 93.9 \mathrm{fmol} / \mathrm{ml}$ versus $417.8 \pm 60.3 \mathrm{fmol} / \mathrm{ml}, \mathrm{p}=0.326$ ) (Fig. 3). However, plasma leptin levels in the smoking group was significantly lower than those in the non-smoking group (434.9 $\pm 41.1 \mathrm{ng} / \mathrm{ml}$ versus $744.0 \pm 45.4 \mathrm{ng} / \mathrm{ml}, \mathrm{p}=0.0003$ ) (Fig. 4).

\section{DISCUSSION}

The present study demonstrated that both food intake and body weight gain were significantly suppressed from the first week to the final week of cigarette smoke exposure. At the end of exposure in the smoking group plasma acyl ghrelin levels were significantly higher while the

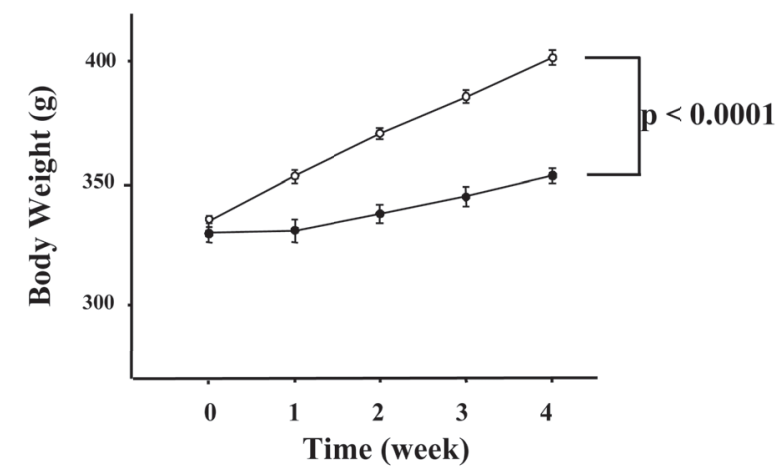

Fig. 2. Effects of cigarette smoke exposure on body weight in WKY rats. Circles show the mean values of the non-exposed group, while solid dots are those of the smoke-exposure group. Each point indicates the mean \pm S.D. of 10 animals. Data were analyzed by two-way ANOVA. The cigarette smoke-exposure group significantly differed from the cigarette smoke-unexposed group $(\mathrm{p}<0.0001)$.

plasma leptin levels were significantly lower than those in the non-smoking group. However, there was no difference in the plasma des-acyl ghrelin levels in both groups.

Cigarette smoke decreases food intake and body weight gain across species humans, rats, mice, and hamsters. It has been suggested that during exposure to cigarette smoke decreased NPY levels in the hypothalamus partially contributed to anorexia (Chen et al., 2005, 2006) while an increased basal metabolic rate suppressed body weight gain in cigarette smokers (Moffatt and Owens, 1991). Additionally, some studies have demonstrated that nicotine administration decreases body weight and caloric intake (Wager-Srdar et al., 1984; Grunberg, et al., 1986; Hajek et al., 1988; Belliger et al., 2010), which were related to a decrease of NPY concentration in the hypothalamus (Frankish et al., 1995). In the present study, animals were exposed with cigarette smoke twice a day, followed by evaluation by the method one of the present authors Kubo and his colleagues (Tanaka et al., 2004) have reported. The report demonstrated that the plasma nicotine levels in the rats exposed to cigarette smoke were elevated to similar nicotine levels of smokers (Tanaka et al., 2004). Therefore, the decreased food intake observed in the present study is thought to represent an inhibition of appetite loss in smokers.

Energy homeostasis is closely regulated by a complex network of peripheral mediators, neuropeptides, cytokines, and hormones, such as ghrelin and leptin. Ghrelin, an endogenous growth hormone (GH)-releasing peptide, was isolated from the stomach (Kojima et al., 1999) and 
Cigarette smoke changes ghrelin and leptin levels

A)

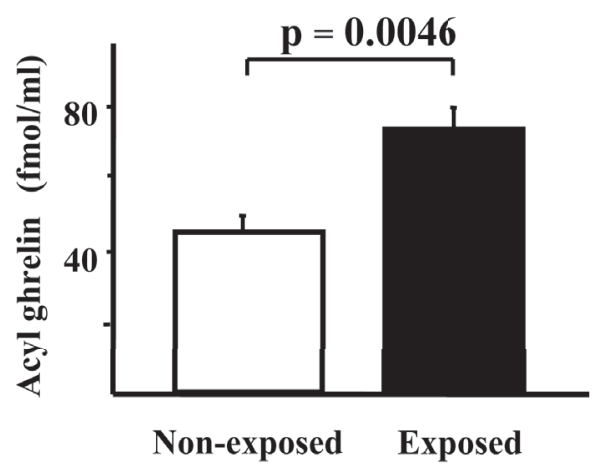

B)

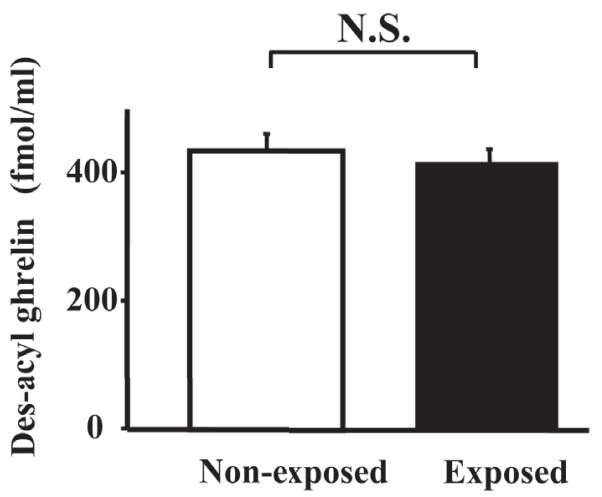

Fig. 3. Influences of cigarette smoke exposure on ghrelin levels in plasma. The outlined bars show the group not exposed to cigarette smoke, while the solid bars show those the smoke-exposed group. Each value indicates the mean \pm S.D. of 10 animals. Data were analyzed by the Mann-Whitney U test. A) In acyl ghrelin levels the cigarette smoke-exposed group significantly differed from the cigarette smoke-unexposed group, $p=0.0046 . \mathrm{B}$ ) in des-acyl ghrelin levels there was no significant difference in both groups.

was shown to cause a positive energy balance by reducing fat utilization through GH-independent mechanisms (Nakazato et al., 2001). In addition, an administration of ghrelin has been shown to elicit the potency, namely, the long-lasting stimulation of food intake through stimulating NPY/AgRP and pro-opiomelanocortin (POMC) neurons in the hypothalamic arcuate nucleus in human and animals (Tschop et al., 2000; Wren et al., 2000; Shintani et al., 2001). Ghrelin has been proved to circulate in both acylated and desacylated form. Of the circulating ghrelin forms, the acylated one (acyl ghrelin) is thought to be essential for ghrelin biological activity (Hosoda et al., 2003), although the function of the desacylated one (des-acyl ghrelin) has not been fully elucidated. Leptin, one of the peptides derived from adipocytes, is produced in differentiated adipocytes and suppresses NPY neurons resulting in an inhibition of appetite (Halaas et al., 1995). An enhancement of energy expenditure was shown to cause a negative energy balance (Collins et al., 1996). Ghrelin and leptin have shown to antagonize each other on the hypothalamic NPY-Y1 receptor pathway in animal experiments (Shintani et al., 2001).

Therefore, the present study suggests that during exposure to cigarette smoke, acyl ghrelin and leptin levels may change to compensate for negative energy balance caused by cigarette smoke. Additionally, the present study suggests that the plasma levels of both acyl ghrelin and leptin may change to stimulate the suppressed NPY pathway during exposure to cigarette smoke. Further investigation regarding the relationship of ghrelin and leptin in the reg-

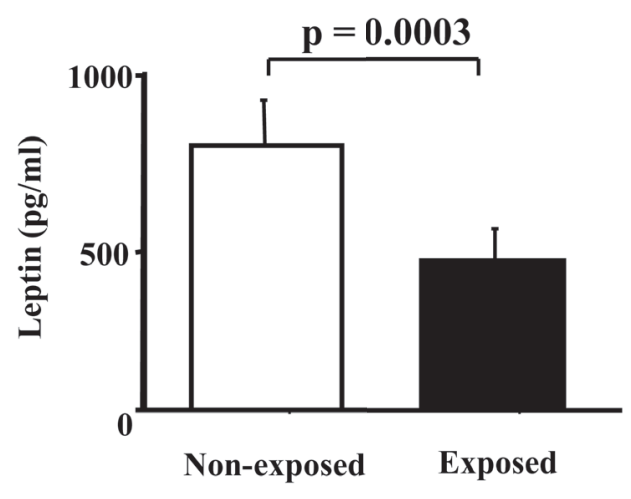

Fig. 4. Influences of cigarette smoke exposure on leptin level in plasma. The outlined bars show the group not exposed to cigarette smoke, while the solid bars show the smoke-exposed group. Each value indicates the mean \pm S.D. of 10 animals. Data were analyzed by the Mann-Whitney U test. The cigarette smoke-exposed group significantly differed from the cigarette smokeunexposed group, $\mathrm{p}=0.0002$.

ulation of food intake during exposure to cigarette smoke is needed.

Besides the negative energy balance cigarette smoke itself may contribute to the changes in plasma acyl ghrelin and leptin levels. In this study there may be only few direct effects of cigarette smoke because we measured the plasma levels $12 \mathrm{hr}$ after final exposure when \% CO$\mathrm{Hb}$ returned to the baseline as shown at Table 1. However nicotine may possibly contribute to the changes in plasma 


\section{K. Tomoda et al.}

Table 2. Effects of cigarette smoke exposure on anti-oxidant/ oxidant balance in plasma.

\begin{tabular}{lcc}
\hline & Non-exposed & Exposed \\
\hline OXY (HCLO $\mu \mathrm{mol} / \mathrm{ml})$ & $322 \pm 9.1$ & $359 \pm 14.8$ \\
d-ROM (Carr unit) & $356 \pm 17.5$ & $325 \pm 18.6$ \\
OXY/d-ROM & $0.91 \pm 0.03$ & $1.11 \pm 0.06^{*}$ \\
\hline
\end{tabular}

OXY: Oxy-adsorbent assay, index of anti-oxidant capacity. d-ROM: Diacron reactive oxygen metabolites, index of oxidative stress. : $\mathrm{p}<0.05$ vs. controls; Values are expressed as means \pm S.D.. The oxidative status and total anti-oxidant capacity were determined by Oxy-absorbent test and d-ROMs test on fresh blood samples, taken from 10 rats, $12 \mathrm{hr}$ after the final cigarette smoke exposure. Date given in the table are means \pm S.D.. ${ }^{*} p<0.05$ versus baseline values analyzed by the Mann-Whitney U test.

acyl ghrelin and leptin levels. The effect of nicotine on circulating leptin levels is controversial. Administration of nicotine to rats decreases plasma leptin levels ( $\mathrm{Li}$ and Kane, 2003) while plasma leptin levels in long-term user of nicotine gum are elevated (Eliasson and Smith, 1991). The effects of nicotine on plasma ghrelin levels have not been studied yet. Further investigation about effects of nicotine on production of ghrelin and leptin is needed.

The function of des-acyl ghrelin has not been cleared, because it has been reported that des-acyl ghrelin might activate orexin and stimulate appetite (Toshinai et al., 2006) while des-acyl ghrelin has been proved to not only enhance peristaltic movements but also suppress food intake (Asakawa et al., 2005). The present study demonstrated that the des-acyl ghrelin levels were unchanged after the exposure to cigarette smoke. There was no significant relationship between the des-acyl ghrelin levels and food intake, suggesting that they are not related to changes in food intake during a 4-week exposure to cigarette smoke.

In underweight patients with COPD, anorexia nervosa, and cancer cachexia, plasma ghrelin levels increased (Itoh et al., 2004; Otto et al., 2001; Shimizu et al., 2003), while plasma leptin levels decreased (Takabatake et al., 1999; Schols et al., 1999; Grinspoon et al., 1996; Simons et al., 1997). Malnutrition has been recognized as one of the systemic effects in COPD, because it has been proved to be not only related with clinical findings but also to be an independent prognostic factor (Agusti et al., 2002). However while it has not been fully elucidated how malnutrition develops in COPD (Agusti et al., 2002), the systemic effects by cigarette smoke are thought to partially contribute to the development of COPD and its systemic effects (Fabbri et al., 2007). In present study emphy- sematous lesions have not been found after four weeks exposure of cigarette smoke (unpublished data). However negative energy balances with changes in plasma ghrelin and leptin levels were similar in those with underweight patients with COPD. These results may support the hypothesis that the systemic rather than only intrapulmonary effects of cigarette smoke may contribute to development of COPD and its systemic effects.

The present study did not clarify the effects of changes in plasma ghrelin and leptin, but after 4 weeks of exposure the ratio of antioxidant to oxidant increased. Some reports indicate that ant-oxidants in smokers might be enhanced compared with non-smokers, from the results of measuring the rates of accumulation of ascorbic acid and dehydroascorbate in alveolar macrophages (McGowan et al., 1984) and contents of glutathione and catalase and protection endothelial cells from hydrogen peroxide in erythrocytes in smokers (Toth et al., 1986). It has been not fully elucidated how anti-oxidant activities are increased in smokers. Recently ghrelin has been proved to have anti-inflammatory effects (Ersahin et al., 2010). Elevated ghrelin levels may be related to an increased ratio of antioxidant to oxidant. Further investigations are needed to determine the relationship between ghrelin and systemic inflammation during exposure to cigarette smoke.

In summary, during 4 weeks of exposure to cigarette smoke in WKY rats, food intake and body weight gain were suppressed, while plasma acyl ghrelin levels increased and plasma leptin levels decreased. However, the plasma des-acyl ghrelin levels were not affected by cigarette smoke exposure. Acyl ghrelin and leptin levels may change to compensate for negative energy balance induced by cigarette smoke.

\section{ACKNOWLEGDGMENTS}

This study was partly supported by a grant to the Respiratory Failure Research Group from the Japanese Ministry of Health, Labor and Welfare.

The authors are indebted to Professor and Chairman J. Patrick Barron of Department of the International Medical Communication Center of Tokyo Medical University for his review of this manuscript.

\section{REFERENCES}

Agustí, A.G., Sauleda, J., Miralles, C., Gomez, C., Togores, B., Sala, E., Batle, S. and Busquets, X. (2002): Skeletal muscle apoptosis and weight loss in chronic obstructive pulmonary disease. Am. J. Respir. Crit. Care. Med., 166, 485-489.

Albanes, D., Jones, D.Y., Micozzi, M.S. and Mattson, M.E. (1987): Associations between smoking and body weight in the US pop- 
Cigarette smoke changes ghrelin and leptin levels

ulation: analysis of NHANES II. Am. J. Pub. Health., 77, 439444.

Alberti, A., Bolognini, L., Macciantelli, D. and Carratelli, M. (2000): The radical cation of N,N- diethylpara-phenylendiamine: a possible indicator of oxidative stress in biological samples. Research of Chemical Intermediates, 26, 253-267.

Asakawa, A., Inui, A., Fujimiya, M., Sakamaki, R., Shinfuku, N., Ueta, Y., Meguid, M.M. and Kasuga, M. (2005): Stomach regulates energy balance via acylated ghrelin and desacyl ghrelin. Gut., 54, 18-24.

Belliger, L.L., Wellman, P.J., Harris, R.B., Keiso, E.W., Kramer, P.R. (2010): The effects of chronic nicotine on meal patterns, food intake, metabolism and body weight of male rats. Pharmacol. Biochem. Behav., 95, 92-99.

Cesarone, M.R., Belcaro, G., Carratelli, M., Cornelli, U., De Sanctis, M.T., Incandela, L., Barsotti, A., Terranova, R. and Nicolaides, A. (1999): A simple test to monitor oxidative stress. Int. Angiol., 18, 127-130.

Chen, H., Vlahos, R., Bozinovski, S., Jones, J., Anderson, G.P. and Morris, M. (2005): Effect of short-term cigarette smoke exposure on body weight, appetite and brain neuropeptide $\mathrm{Y}$ in mice. Neuropsychopharmacology, 30, 713-719.

Chen, H., Hansen, M.J., Jones, J.E., Vlaos, R., Bozinovski, S., Anderson, G.P. and Morris, M.J. (2006): Cigarette smoke exposure reprograms the hypothalamic neuropeptide $\mathrm{Y}$ axis to promote weight loss. Am. J. Respir. Crit. Care. Med., 173, 12481254.

Chen, H., Hansen, M.J., Jones, J.E., Vlahos, R., Bozinovski, S., Anderson, G.P. and Morris, M.J. (2007): Regulation of hypothalamic NPY by diet and smoking. Peptides., 28, 384-389.

Collins, S., Kuhn, C.M., Petro, A.E., Swick, A.G., Chrunyk, B.A. and Surwit, R.S. (1996): Role of leptin in fat regulation. Nature., 380, 677.

Cole, P. (1981): Smoking habits and carbon monoxide. In Smoking and arterial disease: (Greenhalgh, R. M., ed.), pp.74-83, Pitman Medical, London.

Eliasson, B. and Smith, U. (1999): Leptin levels in smokers and long-term users of nicotine gum. Eur. J. Clin. Invest., 29, 145152.

Ersahin, M., Toklu, H.Z., Erzik, C., Centinel, S., Akakin, D., Velioglu-Ogunc, A., Tetik, S., Ozdemir, Z.N., Sener, G. and Yegen, B.C. (2010): The anti-inflammatory and neuroprotective effects of ghrelin in subarachnoid hemorrhage-induced oxidative brain damage in rats. J. Neurotrauma., 27, 1143-1155.

Fabbri, L.M. and Rabe, K.F. (2007): From COPD to chronic systemic inflammatory syndrome? Lancet., 370, 797-799.

Frankish, H.M., Dryden, S., Wang, Q., Bing, C., MacFarlane, I.A. and Williams, G. (1995): Nicotine administration reduces neuropeptide $\mathrm{Y}$ and neuropeptide $\mathrm{Y}$ mRNA concentrations in the rat hypothalamus: NPY may mediate nicotine's effects on energy balance. Brain. Res., 694, 139-146.

Fulkerson, J.A. and French, S.A. (2003): Cigarette smoking for weight loss or control among adolescents: gender and racial/ethnic differences. J. Adolesc. Health., 32, 306-313.

Grinspoon, S., Gulick, T., Askari, H., Landt, M., Lee, K., Anderson, E., Ma, Z., Vignati, L., Bowsher, R., Herzog, D. and Klibanski, A. (1996): Serum leptin levels in women with anorexia nervosa. J. Clin. Endocrinol. Metab., 81, 3861-3863.

Grunberg, N.E., Bowen, D.J. and Winders, S.E.(1986): Effects of nicotine on body weight and food consumption in female rats. Psychopharmacology, 90, 101-105.

Halaas, J.L., Gajiwala, K.S., Maffei, M., Cohen, S.L., Chait, B.T.,
Rabinowitz, D., Lallone, R.L., Burley, S.K. and Friedman, J.M. (1995): Weight-reducing effects of the plasma protein encoded by the obese gene. Science, 269, 543-546.

Hajek, P., Jackson, P. and Belcher, M. (1988): Long-term use of nicotine chewing gum. Occurrence, determinants, and effect on weight gain. JAMA, 260, 1593-1596.

Hosoda, H., Kojima, M., Mizushima, T., Shimizu, S. and Kangawa, K. (2003): Structural divergence of human ghrelin. Identification of multiple ghrelin-derived molecules produced by post-translational processing. J. Biol. Chem., 278, 64-70.

Itoh, T., Nagaya, N., Yoshikawa, M., Fukuoka, A., Takenaka, H., Shimizu, Y., Haruta, Y., Oya, H., Yamagishi, M., Hosoda, H., Kangawa, K. and Kimura, H. (2004): Elevated plasma ghrelin level in underweight patients with chronic obstructive pulmonary disease. Am. J. Respir. Crit. Care. Med., 170, 879-882.

Klesges, R.C., Meyers, A.W., Klesges, L.M. and La Vasque, M.E. (1989): Smoking, body weight, and their effects on smoking behavior: a comprehensive review of the literature. Psychol. Bull., 106, 204-230.

Kojima, M., Hosoda, H., Date, Y., Nakazato, M., Matsuo, H. and Kangawa, K. (1999): Ghrelin is a growth-hormone-releasing acylated peptide from stomach. Nature, 402, 656-660.

Li, M.D. and Kane, J.K. (2003): Effect of nicotine on the expression of leptin and forebrain leptin receptors in the rat. Brain. Res. 991, 223-231.

McGowan, S.E., Parenti, C.M., Hoidal, J.R. and Niewoehner, D.E. (1984): Ascorbic acid content and accumulation by alveolar macrophages from cigarette smokers and nonsmokers. J. Lab. Clin. Med., 104, 127-134.

Moffatt, R.J. and Owens, S.G. (1991): Cessation from cigarette smoking: changes in body weight, body composition, resting metabolism, and energy consumption. Metabolism., 40, 465470.

Nakazato, M., Murakami, N., Date, Y., Kojima, M., Matsuo, H., Kangawa, K. and Matsukura, S. (2001): A role for ghrelin in the central regulation of feeding. Nature, 409, 194-198.

Otto, B., Cuntz, U., Fruehauf, E., Wawarta, R., Folwaczny, C., Riepl, R.L., Heiman, M.L., Lehnert, P., Fichter, M. and Tschöp, M. (2001): Weight gain decreases elevated plasma ghrelin concentrations of patients with anorexia nervosa. Eur. J. Endocrinol., 45, 669-673.

Schols, A.M., Creutzberg, E.C., Buurman, W.A., Campfield, L.A., Saris, W.H. and Wouters, E.F.Ma. (1999): Plasma leptin is related to proinflammatory status and dietary intake in patients with chronic obstructive pulmonary disease. Am. J. Respir. Crit. Care. Med., 160, 1220-1226.

Shimizu, Y., Nagaya, N., Isobe, T., Imazu, M., Okumura, H., Hosoda, H., Kojima, M., Kangawa, K. and Kohn, N. (2003): Increased plasma ghrelin level in lung cancer cachexia. Clin. Cancer. Res., 9, 774-778.

Shintani, M., Ogawa, Y., Ebihara, K., Aizawa-Abe, M., Miyanaga, F., Takaya, K., Hayashi, T., Inoue, G., Hosoda, K., Kojima, M., Kangawa, K. and Nakao, K. (2001): Ghrelin, an endogenous growth hormone secretagogue, is a novel orexigenic peptide that antagonizes leptin action through the activation of hypothalamic neuropeptide Y/Y1 receptor pathway. Diabetes, 50, 227-232.

Simons, J.P., Schols, A.M., Campfield, L.A., Wouters, E.F.M. and Saris, W.H. (1997) : Plasma concentration of total leptin and human lung-cancer-associated cachexia. Clin. Sci., 93, 273-277.

Takabatake, N., Nakamura, H., Abe, S., Hino, T., Saito, H., Yuki, H., Kato, S. and Tomoike, H. (1999): Circulating leptin in patients with chronic obstructive pulmonary disease. Am. J. Respir. Crit. 


\section{K. Tomoda et al.}

Care. Med., 159, 1215-1219.

Tanaka, T., Ohno, N., Kita, T., Kubo, K., Yonetani, Y. and Nakashima, T. (2004): Pharmacodynamic effects of chronic cigarette smoke exposure in spontaneous hypertensive rats. Methods Find. Exp. Clin. Pharmacol., 26, 9-18.

Tomoda, K., Kubo, K., Asahara, T., Andoh, A., Nomoto, K., Nishii, Y., Yamamoto, Y., Yoshikawa, M. and Kimura, H. (2011): Cigarette smoke decreases organic acids levels and population of bifidobacterium in the caecum of rats. J. Toxicol. Sci., 36, 261-266.

Toshinai, K., Yamaguchi, H., Sun, Y., Smith, R.G., Yamanaka, A., Sakurai, T., Date, Y., Mondal, M.S., Shimbara, T., Kawagoe, T., Murakami, N., Miyazato, M., Kangawa, K. and Nakazato, M. (2006): Des-acyl ghrelin induces food intake by a mechanism independent of the growth hormone secretagogue receptor. Endocrinology, 147, 2306-2314

Toth, K.M., Berger, E.M., Beehler, C.J. and Repine, J.E. (1986): Erythrocytes from cigarette smokers contain more glutathione and catalase and protect endothelial cells from hydrogen peroxide better than do erythrocytes from nonsmokers. Am. Rev. Respir. Dis., 134, 281-284.

Tschop, M., Smiley, D.L. and Heiman, M.L. (2000): Ghrelin induces adiposity in rodents. Nature, 407, 908-913.

Vassalle, C., Pratali, L., Boni, C., Mercuri, A. and Ndreu, R.(2008): An oxidative stress score as a combined measure of the prooxidant and anti-oxidant counterparts in patients with coronary artery disease. Clin. Biochem., 41, 1162-1167.

Wager-Srdar, S.A., Levine, A.S., Morley, J.E., Hoidal, J.R. and Niewoehner, D.E. (1984): Effects of cigarette smoke and nicotine on feeding and energy. Physiol. Behav., 32, 389-395.

Wren, A.M., Small, C.J., Ward, H.L., Murphy, K.G., Dakin, C.L., Taheri, S., Kennedy A.R., Roberts, G.H., Morgan, D.G.A., Ghatei, M.A. and Boom, S.R. (2000): The novel hypothalamic peptide ghrelin stimulates food intake and growth hormone secretion. Endocrinology, 141, 4325-4328. 